\title{
Limited evidence for differential reproductive fitness of wild Atlantic cod in areas of high and low salmon farming density
}

\author{
Luke T. Barrett ${ }^{1, *}$, Stephen E. Swearer ${ }^{1}$, Torstein Harboe ${ }^{2}$, Ørjan Karlsen ${ }^{2}$, \\ Sonnich Meier ${ }^{2}$, Tim Dempster ${ }^{1}$
}

${ }^{1}$ School of BioSciences, University of Melbourne, Melbourne, Victoria 3010, Australia

${ }^{2}$ Institute of Marine Research, 5005 Bergen, Norway

\begin{abstract}
Sea cage fish aquaculture attracts large aggregations of wild fish that feed on farm waste. Fish that associate closely with farms undergo physiological changes, and captive feeding trials indicate possible negative effects on reproductive fitness. However, little is known about the significance of this phenomenon for reproduction in wild fish over larger spatial scales. To assess whether coastal areas with intensive aquaculture impact the fitness of wild fish, we collected Atlantic cod Gadus morhua from 2 areas, 1 with high and 1 with low Atlantic salmon Salmo salar farming density (HFD and LFD, respectively) in southwestern Norway, a region that hosts the world's largest coastal fish aquaculture industry. We conducted a captive spawning trial and compared a range of reproductive fitness metrics. Two fatty acids that occur at high levels in commercial feed, oleic and lineoleic acid, were strongly correlated in the ovaries of HFD fish, but a comparison of lipid profiles between HFD and LFD fish showed no differences in total lipids or essential fatty acids. Although HFD fish were slightly larger than LFD fish and had similar body condition, the volume of eggs produced did not differ, indicating relatively lower reproductive investment by HFD fish. HFD eggs were $5 \%$ smaller than LFD eggs, which did not lead to differential hatching success but may have contributed to HFD larvae being $8 \%$ smaller than their LFD counterparts at $40 \mathrm{~d}$ post spawning. The potential for cumulative effects of smaller eggs and larvae on fitness at later life stages warrants further investigation.
\end{abstract}

KEY WORDS: Fitness - Reproductive performance ' Salmon farming ' Wild fish · Fatty acid composition · Gadus morhua

\section{INTRODUCTION}

Intensive culture of fish within sea cages leads to considerable benthic nutrient loads via spilled feed and waste, providing a trophic subsidy that attracts large and persistent aggregations of 'farmassociated' wild fish (Dempster et al. 2002, 2009, 2010). Individuals may reside in the vicinity of farms for months to years (Uglem et al. 2009, Otterå \& Skilbrei 2014) and during this time are exposed to a variety of environmental changes, including elevated

\footnotetext{
${ }^{*}$ Corresponding author: barrett.luke@gmail.com
}

infection risk from parasites and other pathogens (Dempster et al. 2011, Johansen et al. 2011, Arechavala-López et al. 2013, Glover et al. 2013), artificial lighting regimes that may delay maturation and alter behaviour (Porter et al. 1999, Hansen et al. 2001, McConnell et al. 2010, Otterå \& Skilbrei 2014, Skilbrei \& Otterå 2016, reviewed in Trippel 2010), contamination from chemicals and metals used in aquaculture (Burridge et al. 2010), elevated predation risk due to the abundance of large predatory fish, and where permitted, fishing mortality (Akyol \&

(C) The authors 2018. Open Access under Creative Commons by Attribution Licence. Use, distribution and reproduction are unrestricted. Authors and original publication must be credited. 
Ertosluk 2010, Bagdonas et al. 2012). However, perhaps the most obvious change is the high availability of waste feed that typically results in higher somatic and gonadal condition indices for farm-associated wild fish (e.g. Dempster et al. 2011). In Spain, $67-90 \%$ of fish sampled near sea cages had consumed pellets (Fernandez-Jover et al. 2008), while in Norway, pellets made up 71 and $25 \%$, respectively, of the diet for farm-associated saithe Pollachius virens and Atlantic cod Gadus morhua in Norway (Dempster et al. 2011).

Superficially, this trophic subsidy appears to benefit wild fish, but it also results in a dietary shift from marine-derived highly unsaturated omega-3 fatty acids to terrestrially derived omega- 6 fatty acids. This in turn translates to a compositional shift in tissues (Fernandez-Jover et al. 2007, 2011a, ArechavalaLópez et al. 2015, Olsen et al. 2015), and given that dietary lipids are reflected in the egg stores (e.g. Lavens et al. 1999, Czesny et al. 2000, Salze et al. 2005), may result in deficiencies in several of the fatty acids required for reproduction and development. For example, captive feeding trials have found that essential fatty acids 20:5 n-3 (eicosapentaenoic acid, EPA) and 22:6 n-3 (docosahexaenoic acid, DHA), as well as 20:4 $n-6$ (arachidonic acid, AA), are important for fecundity, egg and sperm quality, hatching success, and larval development in fish (Reitan et al. 1994, Rainuzzo et al. 1997, Sargent et al. 1999a,b, Rahman et al. 2014). Dietary deficiencies in these reproductive nutrients contribute to low fertilisation and hatching rates in Atlantic cod (hereafter referred to as 'cod') broodstock relative to their wild counterparts (Salze et al. 2005) and have been linked to changes in egg-quality metrics in turbot Scophthalmus maximus (Lavens et al. 1999), Atlantic halibut Hippoglossus hippoglossus (Mazorra et al. 2003), and cod (Bogevik et al. 2012). Furthermore, while data are lacking for fish, evidence from other taxa indicate that additional effects may become apparent only after fertilisation; sea urchins Echinus acutus reared on commercial salmon feed had higher gonad indices but lower fertilization and larval survival rates, leading to an overall reduction in reproductive fitness (White et al. 2016, 2017a).

The net effect of farm proximity on fitness, whether positive or negative, has a considerable bearing on wild fish populations in farming areas. If trophic subsidies and associated conditions provide a net fitness benefit, farm-associated fish populations will experience higher production than those in neighbouring areas, and farms will act as a population source. However, because farms are highly attractive to many fish species, any decline in fitness in farm-associated wild fish may cause farms to function as 'ecological traps' (Robertson \& Hutto 2006, Hale \& Swearer 2016). Ecological traps are attractive but low-quality habitats that can have significant metapopulation-level impacts by drawing in individuals from higher-quality adjacent habitats, thus acting as attractive population sinks (Hale et al. 2015, Hale \& Swearer 2016). To demonstrate the existence of an ecological trap, we must show that (1) individuals prefer or show equal preference for the putative trap habitat relative to other available habitats and (2) that fitness outcomes in the putative trap habitat are lower than they would have been in the other available habitats (Robertson \& Hutto 2006, Patten \& Kelly 2010). We have strong empirical evidence that ecological traps affect birds and mammals in modified terrestrial and aquatic environments (e.g. Remeš 2003, Weldon \& Haddad 2005, Balme et al. 2010, Kloskowski 2012), but to date there have been very few tests of the theory in the marine environment (Hallier \& Gaertner 2008, Dempster et al. 2011, Sherley et al. 2017), and none that have directly assessed fitness.

Norway operates the largest coastal fish aquaculture industry in the world, with Atlantic salmon Salmo salar production reaching $\sim 1.3$ million tons in 2016 (Norwegian Directorate of Fisheries 2016; www. fiskeridir.no/Akvakultur/Statistikk-akvakultur/Statistiskepublikasjoner/Noekkeltall-for-norsk-havbruksnaering). Fjord cod stocks, which are distinct from the more mobile offshore cod stocks (Robichaud \& Rose 2004), coexist with salmon farming in southern Norway and are at historically low levels, with recent recruitment rates also low (Knutsen et al. 2016). Given these concerns, the population can ill afford a potential ecological trap scenario. The $>300$ active salmon farms in southwestern Norway have widespread effects on fish movement and population distribution and represent hundreds of potential ecological traps for fjord cod. Gadid populations are strongly attracted to salmon grow-out cages (Dempster et al. 2011) and move from farm to farm (Uglem et al. 2009, Otterå \& Skilbrei 2014). This satisfies the first component of an ecological trap assessment by showing preference for the putative trap habitat (Robertson \& Hutto 2006). However, we have no data on direct fitness measures in any farm-associated fish, including gadids.

Farms may impact fitness in wild fish by altering either the survival or reproductive success of individuals. Both pathways are difficult to measure directly in marine fishes, particularly highly mobile broadcast spawning species, and as a result most previous work has relied on proxies such as body condition (Fernan- 
dez-Jover et al. 2007, Dempster et al. 2011). Here we employ a more direct approach by conducting a captive spawning experiment with wild-caught Atlantic cod to investigate whether reproductive fitness differs between areas of high and low salmon farming intensity in southwestern Norway. We assess potential reproductive effects spanning initial adult body condition, ovarian fatty acid profiles, and volumetric egg production, through to egg-quality metrics, hatching rates, and larval-quality metrics, including growth rates, deformity rates, and behaviour.

\section{MATERIALS AND METHODS}

\section{Experimental design and fish husbandry}

The density of salmon farms throughout Norway means that there are no longer any true reference sites for the impacts of salmon farming on highly mobile wild fish in most parts of the country. Instead, we make a comparison between 2 areas with differential farm density, reflecting the typical spectrum of farm exposure for wild fish populations. We collected 2 groups of mature live wild Atlantic cod Gadus morhua from the outer fjords of Hordaland county in southwestern Norway during February 2016. The first group (high farm density; HFD) was collected by commercial fishers and technical staff from 6 locations along an $8 \mathrm{~km}$ stretch of coastline in the Austevoll archipelago and $4 \mathrm{~km}$ away at Reksteren (Fig. 1). HFD collection locations were all in relatively close proximity (300-1200 m) to 6 active salmon farms in an area of generally dense farming activity. The collections took place over $10 \mathrm{~d}$ between 1 and 15 February. The second group (low farm density; LFD) was collected by commercial fishers from 2 locations within the Bømlo archipelago, a neighbouring area with relatively little fish farming activity (Fig. 1), between 5 and 15 February. HFD fish were collected from sites exposed to a mean of 4.0 ha (range 1.5-5.2 ha) of sea cage surface area within $4 \mathrm{~km}$ of their collection location, while LFD collection sites were exposed to mean 0.8 ha (range 0-3.2 ha) within $4 \mathrm{~km}$. These estimates include all sea cages and holding pens, including enclosures that were unstocked at times during 2015 (for locations of active salmon grow-out cages relative to collection sites, see Fig. 1). Seventy-five percent of LFD fish were collected $\sim 9 \mathrm{~km}$ from the nearest salmon cages,
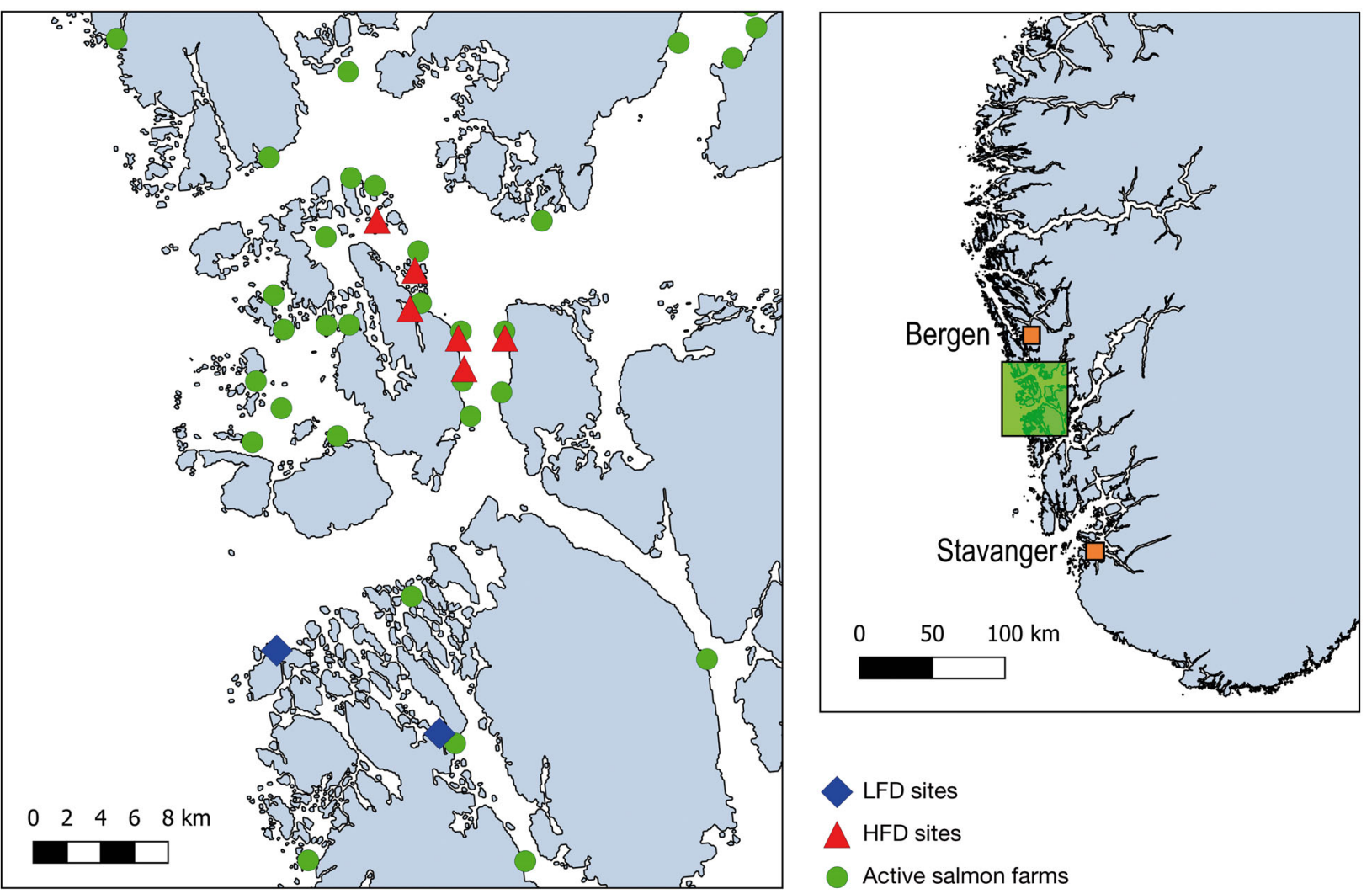

Fig. 1. Collection sites relative to active salmon farms in southwestern Norway. Active outgrowing locations are taken from Norwegian Directorate of Fisheries aquaculture biomass geodata. LED: low farm density; HFD: high farm density 
although it should be noted that the remaining $25 \%$ of LFD fish were collected within $2 \mathrm{~km}$ of a small salmon farm (2340 t capacity). As all fish were pooled within groups, this is likely to reduce overall effect sizes observed in this study. We judged the farm density within $4 \mathrm{~km}$ of the collection site to be a suitable metric of farm exposure based on telemetry data describing the movements of tagged wild coastal cod in Norway and Shetland (Svåsand 1990, Neat et al. 2006, Uglem et al. 2008), but even if some proportion of fish move larger distances, a considerable difference in the average level of farm exposure between HFD and LFD groups will be maintained (Fig. 1). These 2 areas are otherwise comparable environments in terms of gross hydrology, geology, and ecology. Several logistical factors prevented us from including additional sampling areas. Specifically, our need to collect both HFD and LFD fish from shallow water to minimise barotrauma reduced the number of suitable locations, as farms are typically placed in much deeper water. We were also restricted to areas with similar latitude and water temperature to minimise temporal effects on spawning (Kjesbu 1994). In consideration of this geographic restriction, we consider our results to be representative of outer Hardangerfjord but with relevance for similar systems worldwide.

Fish were captured using gill nets and fyke nets over reef or mixed sand-reef substrates at 5-30 m depth and held in marine net pens, unfed, until the commencement of the experiment. The experiment was conducted at the Austevoll Research Station, Norwegian Institute of Marine Research (IMR). On 24 February 2016, we sedated all fish using $20 \mathrm{~g} \mathrm{l}^{-1}$ tricaine methanesulfonate (MS-222: Finquel). Fish with unhealed injuries or other welfare concerns were killed with a blow to the head while sedated. We recorded length, wet weight, and sex of the remaining fish, inserted a passive integrated transponder (PIT) tag into the peritoneal cavity of every fish (allowing us to track individual weight loss between the start and finish of spawning), and took ovarian biopsies from all females for storage at $-80^{\circ} \mathrm{C}$. Fiftyfour females and 24 males were taken from each farm density group and allocated randomly among 6 cylindrical $7 \mathrm{~m}^{3}$ tanks per group (9 females and 4 males per tank, total 12 tanks).

Tanks were supplied with $6-8^{\circ} \mathrm{C}$ sand-filtered and aerated seawater from $168 \mathrm{~m}$ depth and exposed to a natural photoperiod through light-reducing shades. Hatchery facilities at IMR Austevoll are described in detail by Karlsen et al. (2015). Winter spawning typically occurs in the dark, during the early hours of the morning every 2-3 d from February to April. Each spawning tank was appended with a cylindrical 1001 egg collection tank that filtered the full volume of the spawning tank outflow via outlets at the top and bottom of the water column. A constant circular flow was maintained within the egg collector to prevent eggs from being pressed against the filter and damaged. The egg collectors were emptied every morning for the duration of spawning and the volume of floating and sinking eggs was recorded.

Fish in this experiment were not fed for the duration of captivity to better preserve any effects of diet prior to capture and to prevent clogging of egg collectors with waste matter. Reduced feeding and significant weight loss is typical for both wild and captive cod during spawning (Lambert \& Dutil 2000), but to improve animal welfare, we removed fish from the experiment early if their body condition dropped below acceptable levels (indicated by loss of muscle mass, cessation of normal swimming behaviour, or unhealed wounds). Eggs were present after the first night of egg collection, indicating that spawning had already begun. Accordingly, some caution must be applied to interpretations of egg production and quality. However, the 2 groups were collected at similar latitudes and housed in almost identical temperatures (the main determinant of spawning commencement time; Kjesbu 1994), while temporal trends in egg production do not suggest differential start or end times between groups (see Fig. 4). Egg production declined gradually toward the end of the spawning season, with the season considered complete when all tanks had failed to produce viable eggs for 4 consecutive days. All fish were humanely killed with a blow to the head while sedated with $20 \mathrm{~g} \mathrm{l}^{-1}$ MS-222 before recording final length and weight.

On 2 occasions during the spawning season (3-4 March and 24 March), we took eggs for incubation and hatching. Up to $350 \mathrm{ml}$ eggs per tank were disinfected in $400 \mathrm{mg} \mathrm{l}^{-1}$ glutaraldehyde for $8 \mathrm{~min}$ to limit harmful bacterial growth (Harboe et al. 1994), and transferred to 701 black polyethylene conical incubators (one per spawning tank) with $0.51 \mathrm{~min}^{-1}$ seawater flow at $6^{\circ} \mathrm{C}$. Each morning during incubation, dead eggs were drained from the bottom of the incubator and measured volumetrically. On 22 March, when the majority of eggs from the first collection had hatched, we took approximately 6000 larvae from each incubator and divided them across duplicate 501 larval feeding tanks (24 tanks in total) at $8^{\circ} \mathrm{C}$. Larvae remaining in the incubators were killed with a lethal dose of MS-222. Larvae were fed size-fractionated copepod nauplii collected from the IMR sea-pond fa- 
cility at Svartatjern. Techniques for harvesting and preparation of copepods for rearing of cod larvae are described in detail by van der Meeren et al. (2014) and Karlsen et al. (2015). Twice daily, larval rearing tanks received 150000 nauplii, with $1.5 \mathrm{ml}$ of algal paste per tank added to improve feeding performance (Naas et al. 1992). The experiment was concluded on 13 April, with early season larvae at Day 42 and late season larvae at Day 21 post fertilisation.

\section{Ovarian fatty acid composition}

We randomly selected 10 ovarian samples per group (LFD and HFD) from the biopsies stored at the beginning of the experiment. The samples weighed 60-100 mg each. All samples were methylated and the respective fatty acid methyl esters were analysed on a HP-7890A gas chromatograph (Agilent) with a flame ionization detector (GC-FID), according to the method described in Meier et al. (2006). The fatty acid 19:0 was added as an internal standard and $2.5 \mathrm{M}$ dry $\mathrm{HCl}$ in methanol was used as a methylation reagent. The methyl esters were extracted using $2 \times$ $2 \mathrm{ml}$ of hexane, and the solution diluted or concentrated to obtain a suitable chromatographic response. One microlitre was injected splitless (the split was opened after $2 \mathrm{~min}$ ) with the injection temperature set to $270^{\circ} \mathrm{C}$. The column was a $25 \mathrm{~m} \times 0.25 \mathrm{~mm}$ fused silica capillary, coated with polyethylene glycol of $0.25 \mu \mathrm{m}$ film thickness, CP-Wax $52 \mathrm{CB}$ (VarianChrompack). Helium (99.9999\%) was used as mobile phase at $1 \mathrm{ml} \mathrm{min}^{-1}$ for $45 \mathrm{~min}$, then $3 \mathrm{ml} \mathrm{min}^{-1}$ for $25 \mathrm{~min}$. The temperature of the flame ionization detector was set at $300^{\circ} \mathrm{C}$. The oven temperature was programmed to hold at $90^{\circ} \mathrm{C}$ for $2 \mathrm{~min}$, then heated to $150^{\circ} \mathrm{C}$ at $30^{\circ} \mathrm{C} \mathrm{m^{-1 }}$ and then to $240^{\circ} \mathrm{C}$ at $2.5^{\circ} \mathrm{C} \mathrm{min}^{-1}$ and held steady for $30 \mathrm{~min}$. Total analysis time was $70 \mathrm{~min}$. Seventy well-defined peaks in the chromatogram were selected, and identified by comparing retention times with a fatty acid methyl ester standard (GLC-463 from Nu-Chek Prep) and retention index maps and mass spectral libraries (GC-MS) (www.chrombox.org/index.html) performed under the same chromatographic conditions as the GC-FID (Wasta \& Mjøs 2013). Chromatographic peak areas were corrected by empirical response factors calculated from the areas of the GLC-463 mixture. The chromatograms were integrated using the EZChrom Elite software (Agilent Technologies). Only the 39 fatty acids that contributed more than $0.1 \%$ of the total fatty acid amount were included in the calculation. The total amount of fatty acids and cholesterol was calculated using the internal standard 19:0.

\section{Reproductive fitness traits}

\section{Body condition and weight loss}

The amount and quality of egg production is likely to depend on fish condition. To allow quantification of any such relationship, we compared body condition between LFD and HFD groups (within sexes) using the relative condition index $K_{\mathrm{rel}}=100 \times\left(W / W_{\mathrm{exp}}\right)$, where $W$ is the measured wet weight of the individual and $W_{\exp }$ is the expected weight (Le Cren 1951). The expected weight was calculated using a power function of the form $W_{\exp }=a L^{b}$ fitted to the full dataset including both LFD and HFD fish (Fig. 2), where

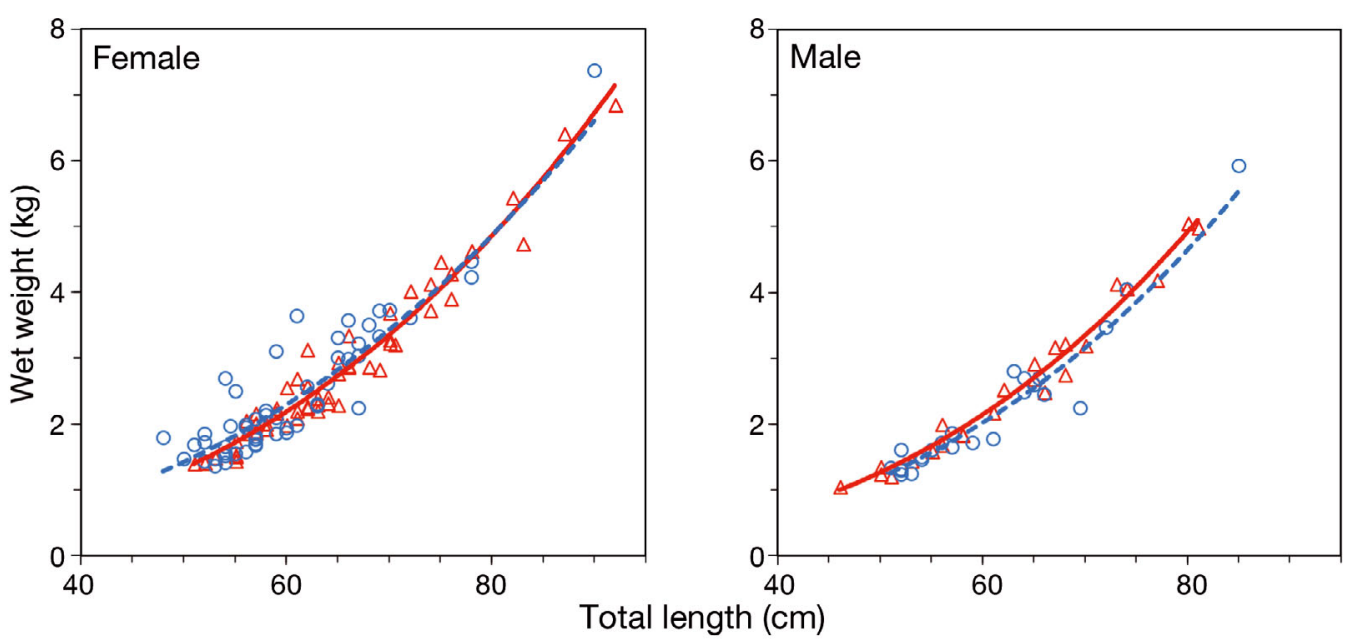

Fig. 2. Weight-at-length relationship for female and male cod used in this study. The best fitting power function $\left(y=a x^{b}\right)$ is shown for each combination of sex and group (HFD: red triangles, solid red fitted line; LFD: blue circles, dashed blue fitted line) 
$L$ is fish length $(\mathrm{cm})$. In this case, $a=0.0272$ and $b=$ $2.76\left(\mathrm{R}^{2}=0.89\right)$. We also calculated proportional weight loss between the start and end of the spawning season. This provides a general index of relative reproductive investment that is typically closely correlated with egg production (e.g. Kjesbu et al. 1996).

\section{Egg production}

We quantified volumetric egg production in terms of daily egg production per tank, both with and without a correction for the size of the females within a given tank, as well as any loss of females during the season. Corrected egg production (relative daily egg production; RDEP) was calculated as follows: RDEP = $V_{\text {egg }} / \mathrm{CFL}$, where $V_{\text {egg }}$ is the volume (ml) of eggs collected from the tank, and CFL is the combined length (cm) of all females in the tank at the time of egg collection. Four females (all HFD) experienced $\leq 10 \%$ weight loss, indicating little or no egg release.

\section{Egg quality}

Viability, fertilization and early development. Egg viability rates were estimated from the proportion of eggs that were floating when the egg collectors were emptied each morning. Fertilisation rates were assessed in subsamples of 100 eggs per tank on 4 occasions (3 occasions for one HFD tank that finished spawning early) during the spawning season (early season: 3-4 and 8-9 March, late season: 17 and 24-25 March), as egg quality typically declines during the spawning season (e.g. Kjesbu et al. 1996). Where egg production was low on a given occasion, we combined fertilisation estimates from 2 successive days. Eggs were scored as fertilised and normal (symmetrical cell divisions), fertilised and abnormal (asymmetry or other abnormalities), or unfertilised.

Egg size and variability. Mean egg size and variability was measured on 2 occasions (3-4 March and 11 April) during the spawning season. Eggs were taken from the egg collectors, stored in $6^{\circ} \mathrm{C}$ seawater for 2-3 $\mathrm{h}$, and placed on a Petri dish and photographed using a digital camera mounted on a light microscope. The images had a $19 \mathrm{~mm}$ field of view at a resolution of $1024 \times 768$ pixels. We measured the diameter of up to 50 eggs per tank (range 18-50) using the image analysis software package ImageJ (Schneider et al. 2012), calibrated against a micrometer slide.

Hatching success. To estimate the proportion of viable eggs that successfully hatch, duplicate egg sub- samples (>100 eggs) were taken from incubators on 2 occasions, early and late in the season (early season: 10 March, Day 8 of incubation; late season: 1 April, Day 9 of incubation) for a hatching trial. Eggs were rinsed with filtered seawater, placed in covered containers filled with $200 \mathrm{ml}$ of filtered seawater, and maintained at $6-7^{\circ} \mathrm{C}$ until hatching was complete. Dead eggs and live and dead hatchlings were scored and removed daily until no viable embryos remained. As there is large variation in growth rates between individual larvae, cannibalism makes it impossible to reliably estimate impacts of farm density on larval survival in this system beyond first feeding.

\section{Larval quality}

Larval development and growth rates. Subsamples of at least 30 larvae per tank were collected $40 \mathrm{~d}$ after spawning (23-28 d post hatching), killed by a lethal dose of MS-222 and stored at $6^{\circ} \mathrm{C}$ until required for photography $(<4 \mathrm{~h})$. Larvae were transferred to a Petri dish with a thin layer of seawater and photographed laterally under dark field illumination on a light microscope with mounted digital camera. The images provided a $12 \mathrm{~mm}$ field of view at a resolution of $1024 \times 768$ pixels. Larvae were measured for length using the ImageJ measuring tool calibrated against a micrometre slide. The measurement was taken along a polyline running from the tip of the snout to the cranial vertebra and along the spine to the end of the caudal peduncle.

Phototaxis. Development of visual and cognitive systems in larvae (at Day 42, ca. 23 d since first feeding) was compared by means of a phototaxis trial in which we tested the proportion of larvae exhibiting behavioural responses to a light gradient. Phototactic responses in this context correlate with larval fitness (e.g. Karlsen \& Mangor-Jensen 2001, Forsgren et al. 2013). Approximately 70 larvae $( \pm 16.9$ SD) were placed in a $60 \times 10 \times 5 \mathrm{~cm}$ tank and allowed to disperse. We then completely covered the tank with black plastic to block any light. After $8 \mathrm{~min}$, we removed the covering on a $10 \times 10 \times 5 \mathrm{~cm}$ end section of the tank (thus exposing it to ambient light from a fluorescent bulb) and scored the number of larvae already present in the end section. This was treated as the control score: the number of larvae present in the end section due to random dispersal without stimulus. The tank was then left for a further $5 \mathrm{~min}$, and the number of larvae in the end section scored again. We then removed the rest of the covering and counted the larvae that had not showed preference 
for light. The trial was conducted for each of the 12 spawning tanks. The change in spatial distribution (the difference in the proportion of larvae in the end section before and after the light treatment) provided a measure of responsiveness to this environmental stimulus.

\section{Statistical analysis}

We compared initial fish size, weight-at-length, and condition $\left(K_{\text {rel }}\right)$ metrics across LFD and HFD groups (Group), using linear analysis of variance models constructed using the ' $\mathrm{lm}$ ' function in $\mathrm{R}(\mathrm{R}$ Core Team 2016). Data were log transformed as necessary to improve normality (and to linearise weightat-length curves). Proportional weight loss was compared between LFD and HFD groups using a beta regression generalised linear model fitted using the betareg package for R (Cribari-Neto \& Zeileis 2010).

We conducted several ovarian fatty acid analyses: initially, we made univariate comparisons of total lipids, cholesterol, and aquafeed markers oleic and linoleic acid across LFD and HFD groups using linear analysis of variance models. We then compared the entire suite of fatty acids across groups using a multivariate permutational analysis of variance (PERMANOVA) fitted to a Euclidean dissimilarity matrix using Primer 6 software (Anderson et al. 2008, White et al. 2017c).

Egg production metrics were compared between treatments and over time using negative binomial generalised linear mixed models fitted using the glmmTMB package (Brooks et al. 2017). Group (farm density group) and Day (sampling day) were fitted as fixed effects. As tanks were sampled repeatedly, non-independence between samples was addressed by including a random intercept term with TankID (tank identity) nested within Group. We report significance of individual model terms within glmmTMB models by comparing the fit of the full model and a null model with the term removed ( $\chi^{2}$ test on $\left.1 \mathrm{df}\right)$.

Effects of farm density on egg-quality metrics were tested by fitting linear mixed models, also using the glmmTMB package. Egg size data were best fitted with a Gaussian model family, while proportion data were fitted using a beta regression family. We included 3 fixed terms: Group, Time (early or late season collections), and MeanFL (mean female length at the tank level, to account for possible effects of female age on egg quality). As with egg production models, we included the nested random intercept term Group or TankID. Proportion or rate responses were analysed at the tank level. Egg size data were analysed at the egg level, with Group, Time, and MeanFL as fixed terms and Group or TankID as a random intercept term. Following the full analysis described above, egg-quality datasets were split into early and late season collections and re-analysed using beta regression models fitted using the betareg package. These results are reported alongside those from the full analyses (Table 2), using a z-test of significance for the Group term.

Data on deformity rates, maximum sizes, and phototaxis were analysed at the tank level using beta regression models fitted with Group and MeanFL as fixed terms (betareg package). The Time and TankID terms were not necessary as all larvae were reared from eggs collected over a $2 \mathrm{~d}$ period early in the season. Larval size data were analysed at the level of individual larvae using a linear mixed model fitted by glmmTMB, with Group and MeanFL as fixed terms and Group or TankID as a random intercept term.

As tank-level analyses come with a cost to statistical power, we calculated Cohen's $d$ effect sizes (calculated using individuals as replicates for fish size and condition, and tanks as replicates for all egg and larval-quality data) to provide an estimate of effects independent of sample size and statistical significance (Cohen 1988).

\section{RESULTS}

\section{Body condition and weight loss}

Female Atlantic cod collected from the HFD environment were significantly longer $(7 \%)$ and heavier $(16 \%)$ than fish from the LFD area, with no difference in body condition between females from HFD and LFD sites (Table 1). HFD males were not significantly different in length or weight from LFD males, but did have a higher body condition than LFD males (Table 1). The log-transformed weight-atlength slope was significantly higher for HFD females than LFD females (although the effect was small: partial $\left.\mathrm{R}^{2}=0.06\right)$, while weight-at-length did not differ for HFD and LFD males (Table S1 in the Supplement at www.int-res.com/articles/suppl/q010 p369_supp.pdf, Fig. 2). During the captive spawning season (mean 37 d LFD, 39 d HFD), females lost $29 \pm$ $9 \%$ body weight, while males lost $18 \pm 6 \%$ (mean \pm SD). LFD females lost more weight than HFD females (mean $\pm \mathrm{SE}: 30 \pm 1.1 \%$ and $27 \pm 1.2 \%$ respectively, $z_{1,9}=2.4, p=0.02$ ), consistent with greater reproductive effort by LFD females. 
Table 1. Body size and condition metrics for low (LFD) and high (HFD) farm density groups at the commencement of the experiment (group means $\pm \mathrm{SE}$ ). $F$ statistics are provided with model and residual degrees of freedom as subscripts. Significant p-values are highlighted in bold. Positive direction indicates that metric was higher in HFD fish

\begin{tabular}{|lccccc|}
\hline & LFD & HFD & Stat $_{\text {df }}$ & $\mathrm{p}$ & Cohen's $d$ \\
\hline Females & $\mathrm{n}=54$ & $\mathrm{n}=54$ & & & \\
Length $(\mathrm{cm})$ & $60.1 \pm 1.1$ & $64.6 \pm 1.2$ & $F_{1,106}=7.2$ & $\mathbf{0 . 0 0 8}$ & +0.49 \\
Weight $(\mathrm{g})$ & $2442 \pm 145$ & $2839 \pm 164$ & $F_{1,106}=4.2$ & $\mathbf{0 . 0 4 3}$ & +0.35 \\
Condition $\left(K_{\text {rel }}\right)$ & $1.03 \pm 0.03$ & $0.98 \pm 0.01$ & $F_{1,106}=3.1$ & 0.08 & -0.34 \\
Males & $\mathrm{n}=24$ & $\mathrm{n}=24$ & & & \\
Length $(\mathrm{cm})$ & $60.3 \pm 1.2$ & $62.8 \pm 2.0$ & $F_{1,46}=0.9$ & 0.34 & +0.29 \\
Weight $(\mathrm{g})$ & $2204 \pm 148$ & $2624 \pm 243$ & $F_{1,46}=1.7$ & 0.20 & +0.37 \\
Condition $\left(K_{\text {rel }}\right)$ & $0.98 \pm 0.02$ & $1.04 \pm 0.01$ & $F_{1,46}=4.7$ & $\mathbf{0 . 0 4}$ & +0.63 \\
\hline
\end{tabular}

\section{Ovarian fatty acid composition}

We found no evidence that ovarian lipid modification reflected the density of salmon farms, with no significant difference in total fatty acid content or cholesterol content, or in total saturated, monounsaturated, or polyunsaturated fatty acids (Table S2). Likewise, multivariate fatty acid composition was not significantly different between LFD and HFD groups (pseudo- $F_{18}=0.58, p=0.71$; Fig. 3 ). Multidimensional scaling revealed that 3 individuals -1 LFD and 2 HFD - were separated from the main cluster. These 3 fish were not remarkable in size or body condition $\left(57-72 \mathrm{~cm}, 2022-3620 \mathrm{~g}, K_{\text {rel }} 0.99-1.11\right)$, but both HFD fish were high in oleic acid 18:1 (n-9) (15.2 and $17.5 \%)$ and 1 was also high in linoleic acid 18:2 (n-6) $(3.7 \%)$. The outlying LFD fish was also high in linoleic acid $(2.5 \%)$. Both oleic and linoleic acid can indicate consumption of commercial feed (Fernandez-Jover et al. 2011b, White et al. 2017c), and were marginally higher in the HFD group on average $(6 \%$ and $18 \%$ increases, respectively), but this effect was not significant for either oleic acid $\left(F_{1,18}=1.9, \mathrm{p}=0.2\right)$ or linoleic acid $\left(F_{1,18}=0.4, p=0.6\right)$. Levels of these fatty acids were strongly positively correlated with each other in the HFD group (Pearson's $\mathrm{r}=0.90, t_{8}=$ $6.0, p<0.001)$, while this effect was non-significant in the LFD group $\left(\mathrm{r}=0.44, t_{8}=1.4, \mathrm{p}=0.2\right)$. The highest levels of both oleic and linoleic acid $(17.5 \%$ and $3.7 \%$ respectively) occurred in one individual from the HFD group.

\section{Egg production}

Twelve spawning tanks produced a total of $137 \mathrm{l}$ of eggs over the spawning season, with no difference in the total egg volume from LFD and HFD tanks $(11.3 \pm 0.9 \mathrm{l}$ and $11.3 \pm$ 0.7 l, respectively; Fig. 4). A model comparing raw daily egg production between HFD and LFD tanks over time found no effect of the farm density factor $(p=0.08$; Table S3). There was a significant temporal decline in daily egg production ( $p<0.0001$, Fig. 4), and a positive effect of total female length in the tank on daily egg production $(\mathrm{p}<0.0001)$.

The relative daily egg production metric (daily egg production corrected for total female length) also did not significantly differ across groups (LFD: $64.6 \pm 6.2$ cf. HFD: $57.2 \pm 3.4 \mathrm{ml}$ female $\mathrm{m}^{-1} \mathrm{~d}^{-1}$ $\operatorname{tank}^{-1} ; \mathrm{p}=0.52$ ), but again, there was a significant decline over time ( $p<0.0001$, Fig. 4$)$.

Initial female body condition (tank mean values) did not significantly predict either raw daily egg production or relative daily egg production metrics overall ( $p>0.10$ in both cases), or within farm density groups ( $p>0.05$ in each case). However, mean female weight loss during the season was strongly correlated with both egg production metrics ( $p<$ 0.0004 in each case).

\section{Egg quality and survivorship}

The proportion of viable (floating) eggs was almost identical across farm density groups (Tables 2

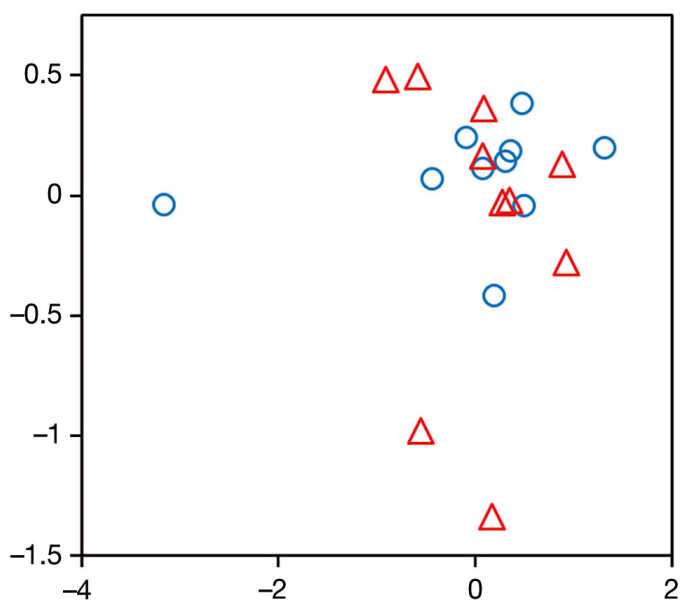

Fig. 3. Multidimensional scaling plot showing dissimilarly (Euclidean distance) of multivariate fatty acid profiles in Atlantic cod ovaries according to salmon farm density. Individuals are grouped by high (HFD; red triangles) and low (LFD; blue circles) salmon farm density. Model stress is 0.08 

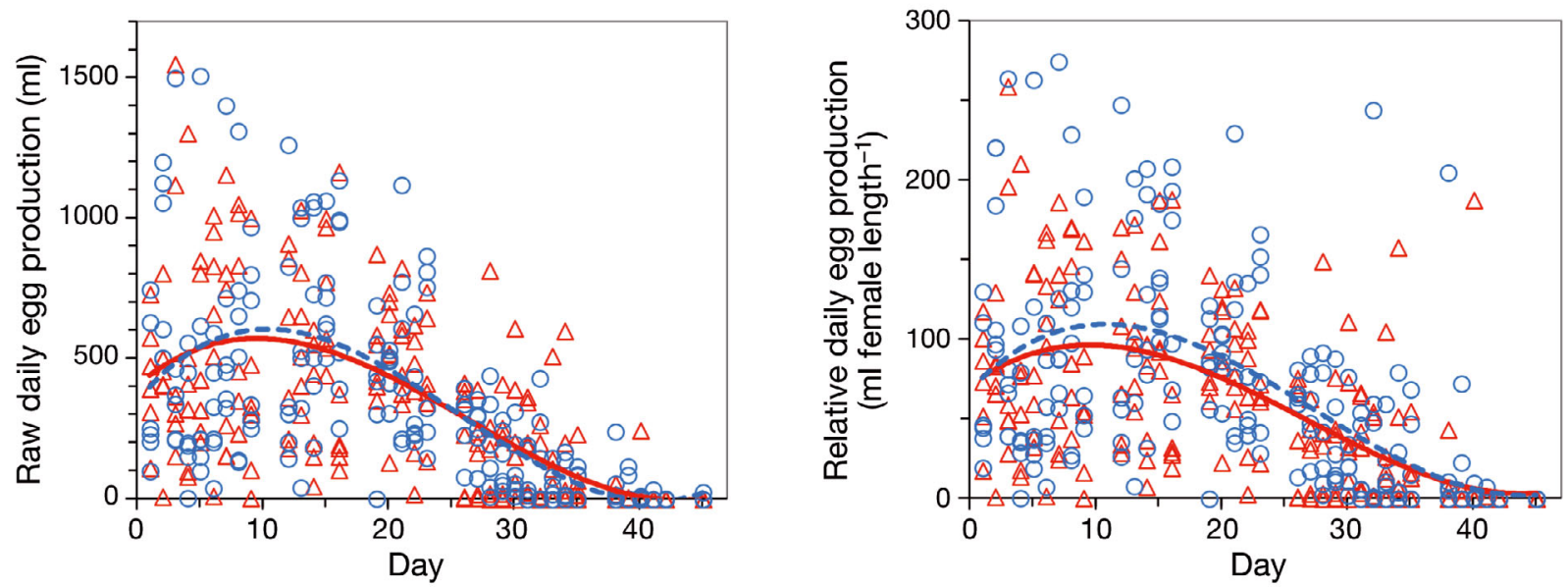

Fig. 4. Daily egg production per tank during the captive spawning period (25 Feb-11 Apr 2016). Tanks are grouped by high (HFD; red triangles, solid red fitted line) and low (LFD; blue circles, dashed blue fitted line) farm density. Production is quantified by raw daily egg volume per tank (left) and with a correction for the total length of females in the tank (right). The temporal trend within groups is fitted by third-order polynomial functions

\& S3), with the viable proportion significantly declining over the season $(p<0.0001)$. Neither mean female length $(p=0.18)$ nor body condition $(p=0.60)$ were correlated with egg viability rates at the tank level, regardless of farm density group.

The LFD group produced larger eggs over the duration of the season (Tables $2 \&$ S3). LFD eggs were $4.8 \%$ larger by diameter at the time of the early season collections, with no significant difference later in the season (Table 2). We did not test for a temporal decline in egg size, as late but not early season samples were fixed in formalin. Again, neither mean female length $(p=0.065)$ nor body condition $(p=0.32)$ were significantly correlated with egg size, regardless of farm density group.

Among the viable proportion, fertilisation rates were similar for LFD and HFD tanks respectively (Tables 2 \& S3), but declined during the season $(\mathrm{p}=$ $0.009)$. Neither mean female length nor body condition significantly predicted fertilisation rates overall ( $p>0.06$ in each case), although the effect of female length was significant within the LFD group $(p=$ $0.04)$. Given the very small difference in egg viability and fertilisation rates between groups, and non-significant effects of male length and body condition on fertilisation rates either overall or within groups ( $p>$ 0.13 in each case), we did not test for differences in sperm quality.

Rates of asymmetrical cell division in pre-blastula eggs did not differ between LFD and HFD groups in either early or late season collections (Tables 2 \& S3). Neither mean female size nor body condition were correlated with egg symmetry ( $p>0.06$ in each case). Mean asymmetry rates did not exceed $10 \%$ in either group on any collection date, although samples ranged from 0 to $53 \%$ asymmetry.

Early season eggs hatched 12-17 d after collection, while late season eggs hatched 14-18 d after collection. Egg survival during incubation prior to the hatching trial did not differ significantly between groups (Tables 2 \& S3). Declines in survivorship between early and late season collections did not differ $(p>0.10)$, nor did the effect of mean female length or body condition ( $p>0.10$ in each case).

Hatching success rates were similar between groups (Tables 2 \& S3), with no decline between early and late season collections. One HFD tank ceased spawning before the late season egg sampling, so late season HFD hatching data come from only 5 tanks.

\section{Larval quality}

Larvae from LFD tanks were $8 \%$ larger than those from HFD tanks (Tables 2 \& S3). Neither mean female size $(p=0.97)$ nor body condition $(p=0.34)$ were correlated with larval size either overall or within farm density groups. The size of the largest larvae from each tank did not differ across farm density groups, nor did the rate of deformities (Tables 2 \& S3). Neither were significantly correlated with mean female length or body condition $(p>0.10$ in each case). Overall rates of larval deformity were $48 \%$ at day 40 from both LFD and HFD groups (Table 2). Most deformities were of the spine (lordosis, kyphosis, or vertebral misalignment) (152/173 deformities), followed by deformities of the jaw 
Table 2. Egg- and larval-quality metrics for cod from low (LFD) and high (HFD) farm density areas (group mean $\pm \mathrm{SE}$ ). Simple test statistics are provided (Stat). Refer to Table S3 for full model summaries. Positive effect sizes indicate that quality was higher in the HFD group. Significance has not been corrected for false discovery rate of multiple comparisons

\begin{tabular}{|c|c|c|c|c|c|c|}
\hline & LFD & HFD & $\begin{array}{c}\mathrm{N} \\
(\mathrm{HFD}, \mathrm{LFD})\end{array}$ & Stat & $\mathrm{p}$ & $\begin{array}{c}\text { Cohen's } \\
d\end{array}$ \\
\hline \multicolumn{7}{|l|}{ Viability rate } \\
\hline Early season & $0.96 \pm 0.01$ & $0.94 \pm 0.03$ & 102,102 & $\mathrm{z}=0.21$ & 0.83 & -0.25 \\
\hline Late season & $0.78 \pm 0.15$ & $0.76 \pm 0.11$ & 70,74 & $\mathrm{z}=0.56$ & 0.56 & -0.19 \\
\hline Overall & $0.87 \pm 0.04$ & $0.85 \pm 0.04$ & 172,176 & $\chi^{2}=0.23$ & 0.61 & -0.14 \\
\hline \multicolumn{7}{|c|}{ Egg diameter ( $\mu \mathrm{m})$ (of viable eggs) } \\
\hline Early season & $1183 \pm 16$ & $1129 \pm 16$ & 257,289 & $\chi^{2}=5.8$ & 0.016 & -1.36 \\
\hline Late season ${ }^{\mathrm{a}}$ & $1261 \pm 30$ & $1210 \pm 13$ & 221,271 & $\tilde{\chi}^{2}=5.3$ & 0.07 & -0.92 \\
\hline Overall & $1222 \pm 20$ & $1166 \pm 16$ & 478,560 & $\chi^{2}=6.5$ & 0.011 & -0.90 \\
\hline \multicolumn{7}{|c|}{ Fertilisation rate (of viable eggs) } \\
\hline Early season & $0.75 \pm 0.04$ & $0.77 \pm 0.03$ & 19,20 & $z=0.68$ & 0.49 & +0.27 \\
\hline Late season & $0.59 \pm 0.09$ & $0.68 \pm 0.06$ & 15,18 & $z=0.47$ & 0.63 & +0.46 \\
\hline Overall & $0.67 \pm 0.08$ & $0.73 \pm 0.04$ & 34,38 & $\chi^{2}=1.0$ & 0.60 & +0.36 \\
\hline \multicolumn{7}{|c|}{ Egg symmetry rate (of fertilised viable eggs) } \\
\hline Early season & $0.92 \pm 0.01$ & $0.90 \pm 0.02$ & 19,20 & $z=0.69$ & 0.49 & -0.29 \\
\hline Late season & $0.88 \pm 0.18$ & $0.88 \pm 0.08$ & 15,18 & $z=0.48$ & 0.63 & -0.10 \\
\hline Overall & $0.90 \pm 0.03$ & $0.89 \pm 0.04$ & 34,38 & $\chi^{2}=0.35$ & 0.84 & -0.08 \\
\hline \multicolumn{7}{|c|}{ Egg survival rate during incubation } \\
\hline Early season & $0.85 \pm 0.03$ & $0.83 \pm 0.05$ & 6,6 & $z=0.66$ & 0.49 & -0.23 \\
\hline Late season & $0.56 \pm 0.11$ & $0.68 \pm 0.09$ & 5,6 & $z=0.48$ & 0.63 & +0.41 \\
\hline Overall & $0.70 \pm 0.08$ & $0.76 \pm 0.06$ & 11,12 & $\chi^{2}=0.01$ & 0.95 & +0.23 \\
\hline \multicolumn{7}{|c|}{ Hatching success rate } \\
\hline Early season & $0.90 \pm 0.03$ & $0.85 \pm 0.03$ & 12,12 & $z=1.56$ & 0.12 & -0.64 \\
\hline Late season & $0.92 \pm 0.03$ & $0.88 \pm 0.08$ & 11,12 & $z=0.15$ & 0.88 & -0.07 \\
\hline Overall & $0.91 \pm 0.02$ & $0.86 \pm 0.04$ & 23,24 & $\chi^{2}=0.18$ & 0.67 & -0.48 \\
\hline \multicolumn{7}{|c|}{ Larval length (mm) } \\
\hline Early season & $6.46 \pm 0.05$ & $5.98 \pm 0.18$ & 180,176 & $\chi^{2}=3.9$ & 0.048 & -1.46 \\
\hline \multicolumn{7}{|c|}{ Max larval length (mm) } \\
\hline Early season & $8.05 \pm 0.17$ & $7.68 \pm 0.21$ & 6,6 & $t_{1,10}=1.32$ & 0.21 & -0.77 \\
\hline \multicolumn{7}{|c|}{ Larval deformity rate } \\
\hline Early season & $0.48 \pm 0.06$ & $0.48 \pm 0.07$ & 6,6 & $z_{1,9}=0.01$ & 0.99 & 0 \\
\hline \multicolumn{7}{|c|}{ Larval phototaxis rate } \\
\hline Early season & $0.71 \pm 0.07$ & $0.67 \pm 0.04$ & 6,6 & $z_{1,9}=0.79$ & 0.43 & -0.28 \\
\hline
\end{tabular}

(15/173) and skull (6/173). Larvae from both groups exhibited phototaxis in response to a horizontal light gradient (proportion in end section before exposure: $0.25 \pm 0.03 \mathrm{cf}$. after exposure: $0.69 \pm 0.04 ; t$-test: $t_{22}=$ $-9.5, \mathrm{p}<0.0001$ ), but we found no evidence that the farm density groups differed in the extent of the phototactic response (Tables $2 \&$ S3), nor any strong evidence for an effect of mean female length or body condition ( $p>0.13$ in each case).

\section{DISCUSSION}

This study presents limited evidence for negative impacts of high salmon farm density on reproductive fitness in the studied Atlantic cod population. Female HFD cod were larger and heavier than LFD fish, but with no consistent changes in female body condition. Effects on ovarian lipid composition were also small and largely limited to 2 HFD individuals. There was no significant difference in egg production, viability, fertilisation rates, symmetry, or hatching success, but eggs from HFD tanks were 5\% smaller and this likely contributed to the observed $-8 \%$ disparity in mean larval length at $40 \mathrm{~d}$ post spawning for the HFD group relative to the LFD group.

Gadid fishes accumulate significant energy reserves for reproduction, with lipids stored primarily in the liver and proteins in muscle tissue (Kjesbu et al. 1991, Lambert \& Dutil 1997). Accordingly, body condition indices during vitellogenesis are typically good predictors of fecundity in coastal cod from this region (Skjæraasen et al. 2006). In our case, mean female size and percentage weight loss during the season positively tracked egg production at the tank level; both were better predictors of egg production than initial female body condition. However, the direction of the body condition trend was positive, and together, our findings are consistent with greater reproductive investment relative to body length by LFD females. Egg-quality metrics revealed similar quality overall in LFD and HFD groups, but with significantly smaller eggs from HFD fish. This was somewhat unexpected, as HFD females were slightly larger; female size and age in cod is usually positively correlated with egg size (e.g. Marteinsdottir \& Steinarsson 1998, Vallin \& Nissling 2000), although body condition can be equally important (Chambers \& Waiwood 1996, Marteinsdottir \& Steinarsson 1998). The egg size effect that we observed did not correspond to any significant decrease in other metrics of egg quality, and the cumulative effect of the more direct metrics (viability, fertilisation, developmental symmetry, survival during incubation, and hatching success) was such that eggs collected from HFD and LFD 
tanks did not differ substantially in their likelihood of successfully hatching (HFD $40 \%$ cf. LFD $37 \%$ ). However, previous studies have indicated that egg size can predict larval quality, with larger size at hatching, faster growth rates, and successful development of the swim bladder leading to a survival advantage for larvae from larger eggs (Knutsen \& Tilseth 1985, Marteinsdottir \& Steinarsson 1998). This prediction was consistent with our larval size data; HFD larvae were $8 \%$ smaller on average than their LFD counterparts $40 \mathrm{~d}$ after spawning.

Larger larvae often exhibit differing responses to stimuli such as light (e.g. Colton \& Hurst 2010). In some fish, phototaxis along a horizontal light gradient correlates positively with other metrics of development (e.g. first feeding: Karlsen \& Mangor-Jensen 2001) and is affected by the environment (Forsgren et al. 2013). In our case, LFD and HFD fish did not differ in their phototactic response to a horizontal light gradient, although the effect was in the direction of the greater phototaxis by LFD larvae (Cohen's $d=0.28$ ). Regardless, even small differences in hatching size and larval growth rates can affect survival during the planktonic stage and even influence post-settlement fitness (e.g. Sclafani et al. 1993, Shima \& Swearer 2010), so it is likely that the HFD larvae in this study would have experienced non-trivial negative fitness effects later in development.

Condition indices for fish in the present study were similar to those from wild-caught fish in the same region prior to the expansion of salmon farming (Botros 1962, cited in Kjesbu 1989). Egg sizes in our study (mean $1.2 \mathrm{~mm}$ ) were at the lower end of those reported by previous captive spawning studies with Norwegian coastal cod (1.2-1.4 mm: Kjesbu et al. 1996, Otterå et al. 2006, van der Meeren \& Ivannikov 2006, Bogevik et al. 2012, Karlsen et al. 2015), but this may be related to the lack of feed during spawning rather than condition at the time of collection (Kjesbu et al. 1990). Egg fertilisation, symmetry, and hatching rates were all within the range of those reported by previous studies (Morgan et al. 1999, van der Meeren \& Ivannikov 2006, Bogevik et al. 2012, Karlsen et al. 2015), while larval growth rates (6.2 mm cf. $7.4 \mathrm{~mm}$ at $25 \mathrm{~d}$ post hatching) were slightly below those reported by Karlsen et al. (2015).

While previous studies have found significant shifts in ovarian fatty acid composition in captive-fed sea bream (Cejas et al. 2003) and farm-associated bogue (L. Martinez-Rubio unpubl. data, cited in FernandezJover et al. 2011a), the absence of such clear effects in this study should not be taken as strong evidence that these fish have not fed at salmon farms. Lipid profiles of the gonads are less affected by diet than those of the liver or muscle tissue, as the gonads are composed almost entirely of phospholipids rather than dietary fatty acids. Accordingly, our analysis of ovarian lipid composition may only have detected effects of a large dietary shift, while the presence of a single active salmon farm near 1 LFD location (affecting $25 \%$ of LFD fish) may have reduced overall differences in fatty acid profiles between HFD and LFD groups. Indirect intake of farm waste via predation of farm-associated invertebrates and fish, combined with dietary sparing and biosynthesis, may also weaken or mask fatty acid signals in fish that are not strongly farm associated (White et al. 2017c). The strong correlation between levels of oleic and linoleic acids in the HFD group (less so in the LFD group) is consistent with (but not necessarily strong evidence for) a spectrum of farm association, with the most strongly farm-associated individuals in the HFD group having higher levels of oleic and linoleic acids than their counterparts in the LFD group. Both oleic and linoleic acid are present in the natural diet but are especially abundant in commercial salmon feed, and captive feeding trials revealed a strong correlation between these 2 fatty acids in muscle, liver, and gonad tissue of saithe fed on salmon feed $(\varnothing$. Karlsen et al. unpubl. data).

Our collection sites were selected to represent levels of farm exposure experienced by cod populations in the southwestern fjords (Fig. 1). Importantly, cod do not associate with farms as closely or persistently as other species (e.g. saithe), and likely do not feed exclusively at farms for extended periods (Dempster et al. 2011), so our experiment was designed to test for effects of farm density on cod whose home ranges at the time of collection overlap with areas of farming influence. Salmon farms have relatively localised nutrient footprints, with acute deposition within 50-250 $\mathrm{m}$ and very diffuse deposition beyond $500 \mathrm{~m}$ (Kutti et al. 2007, Bannister et al. 2016, White et al. $2017 b)$. Accordingly, our collection sites are likely to reflect the 2 dominant types of farm exposure for wild Norwegian fjord cod: temporally dynamic or partial association versus little or no association. Tissue fatty acid profiles in cod are altered within $3 \mathrm{wk}$ of a dietary shift (Kirsch et al. 1998), with vitellogenesis commencing 3-4 mo prior to spawning (Skjæraasen et al. 2006). Individuals that reside within farm footprints throughout vitellogenesis are likely to show the largest shifts in ovarian fatty acid profiles and concomitant effects on reproductive physiology and output. We do not know how long HFD and LFD cod 
have resided at their capture locations, but available telemetry and mark-recapture data indicate that wild coastal cod have relatively restricted home ranges over a scale of weeks and months. Eightyseven percent of tag returns for wild cod released in Heimarkspollen, a $2.9 \mathrm{~km}^{2}$ semi-enclosed fjord in the Austevoll archipelago, were recaptured within the fjord (Svåsand 1990), while in Balsfjord in northern Norway, the majority of wild cod tagged and released at a farm were still present at the same farm 9-12 wk later (Uglem et al. 2008). In the Shetland Isles, 133 wild cod were tagged and released, with $37 / 39$ recaptures over a 2 yr period occurring within $15 \mathrm{~km}$ of the release site (Neat et al. 2006). While some individuals move larger distances and may have spent time in areas that differ from their capture location in terms of farm density, our study only assumes that fish collected from LFD locations will, on average, be less affected by farms than fish from HFD locations.

Previous captive feeding experiments have shown that gadids and other fishes fed commercial diets experience changes in reproductive fitness (e.g. Salze et al. 2005, Bogevik et al. 2012), but very little work has been done to assess potential impacts in a real-world ecological context. Taken together, our findings indicate that salmon farming in this region has some negative effects on the reproductive physiology of Atlantic cod on a fjord-wide scale, with potential cumulative effects of egg and larval size on later developmental stages. More work is needed to track fitness effects later in development, including potential effects of decreased egg and larval size on later life stages. In addition, as our study was restricted in its geographic extent and spatial replication, we are cautious of generalising these findings beyond our study environment. We encourage others to replicate and extend this important line of research. Future work may also consider the other potential pathway for fitness impacts: individual mortality. Mortality may decline due to the provision of a trophic subsidy (Kilambi et al. 1978), or increase due to elevated levels of contamination, infection, or predation at farms. Wild fish aggregations are also an easy target for fishers, and fishing mortality will take on greater importance if the current $100 \mathrm{~m}$ fishing restriction around Norwegian farms is lifted (Bagdonas et al. 2012). Previous studies have employed acoustic tracking to good effect in comparing spatiotemporal movement and mortality rates of Atlantic cod individuals across habitats (Olsen \& Moland 2011, Olsen et al. 2012, Fernández-Chacón et al. 2015), and it would be entirely feasible to apply the same approach to quantify differential mortality rates in wild fish across multiple farm-affected and nonaffected areas.

Data archive. Data are available at https://figshare.com/s/ f26589119217cddfbd4d

Acknowledgements. We thank the staff at IMR Austevoll for their expert advice and assistance in the collection and maintenance of the spawning fish, egg incubation, and feeding of larvae: Margareth Møgster, Stig Ove Utskot, Michal Rejmer, Inger Semb Johansen, Nele Gunkel-Sauer, Kristine Hovland Holm, Yvonne Rong, Terje van der Meeren, Tord Skår, Velimir Nola and Glenn Sandtorv. We also thank the staff and students at Austevoll High School for their assistance in transporting live fish to the research station. Theresa Aase prepared the fatty acid analysis. Camille White provided useful comments on lipid data. Francisca Samsing assisted with the creation of figures. The manuscript was improved by comments from 3 anonymous reviewers. All procedures were conducted in accordance with Norwegian animal welfare regulations by experienced personnel. This project was funded by the Sustainable Aquaculture Laboratory, University of Melbourne, and the Norwegian Seafood Research Fund (Fiskeri og Havbruksnæringens Forskningsfond).

\section{LITERATURE CITED}

Akyol O, Ertosluk O (2010) Fishing near sea-cage farms along the coast of the Turkish Aegean Sea. J Appl Ichthyology 26:11-15

Anderson M, Gorley R, Clarke R (2008) Permanova+ for Primer: guide to software and statistical methods. Primer-E, Plymouth

Arechavala-López P, Sánchez-Jerez P, Bayle-Sempere JT, Uglem I, Mladineo I (2013) Reared fish, farmed escapees and wild fish stocks - a triangle of pathogen transmission of concern to Mediterranean aquaculture management. Aquacult Environ Interact 3:153-161

Arechavala- López P, Sæther BS, Marhuenda-Egea F, Sánchez-Jerez P, Uglem I (2015) Assessing the influence of salmon farming through total lipids, fatty acids, and trace elements in the liver and muscle of wild saithe Pollachius virens. Mar Coast Fish 7:59-67

Bagdonas K, Humborstad OB, Løkkeborg S (2012) Capture of wild saithe (Pollachius virens) and cod (Gadus morhua) in the vicinity of salmon farms: three pot types compared. Fish Res 134-136:1-5

Balme GA, Slotow R, Hunter LTB (2010) Edge effects and the impact of non-protected areas in carnivore conservation: leopards in the Phinda-Mkhuze Complex, South Africa. Anim Conserv 13:315-323

Bannister RJ, Johnsen IA, Hansen PK, Kutti T, Asplin L (2016) Near- and far-field dispersal modelling of organic waste from Atlantic salmon aquaculture in fjord systems. ICES J Mar Sci 73:2408-2419

* Bogevik AS, Natário S, Karlsen Ø, Thorsen A, Hamre K, Rosenlund G, Norberg B (2012) The effect of dietary lipid content and stress on egg quality in farmed Atlantic cod Gadus morhua. J Fish Biol 81:1391-1405

Botros G (1962) Die Fruchtbarkeit des Dorsches (Gadus morhua L.) in der westlichen Ostsee und den westnor- 
wegischen Gewässern. Kieler Meeresforsch 18:67-80

Brooks ME, Kristensen K, van Benthem KJ, Magnusson A and others (2017) Modeling zero-inflated count data with glmmTMB. bioRxiv:132753

Burridge L, Weis JS, Cabello F, Pizarro J, Bostick K (2010) Chemical use in salmon aquaculture: a review of current practices and possible environmental effects. Aquaculture 306:7-23

Cejas JR, Almansa E, Villamandos JE, Badía P, Bolaños A, Lorenzo A (2003) Lipid and fatty acid composition of ovaries from wild fish and ovaries and eggs from captive fish of white sea bream (Diplodus sargus). Aquaculture 216:299-313

Chambers RC, Waiwood KG (1996) Maternal and seasonal differences in egg sizes and spawning characteristics of captive Atlantic cod, Gadus morhua. Can J Fish Aquat Sci 53:1986-2003

Cohen J (1988) Statistical power analysis for the behavioral sciences, 2nd edn. Erlbaum, Hillsdale

Colton AR, Hurst TP (2010) Behavioral responses to light gradients, olfactory cues, and prey in larvae of two North Pacific gadids (Gadus macrocephalus and Theragra chalcogramma). Environ Biol Fishes 88:39-49

Cribari-Neto F, Zeileis A (2010) Beta egression in R. J Stat Softw 34:1-24

Czesny S, Dabrowski K, Christensen JE, Van Eenennaam J, Doroshov S (2000) Discrimination of wild and domestic origin of sturgeon ova based on lipids and fatty acid analysis. Aquaculture 189:145-153

* Dempster T, Sánchez-Jerez P, Bayle-Sempere JT, GiménezCasalduero F (2002) Attraction of wild fish to sea-cage fish farms in the south-western Mediterranean Sea: spatial and short-term temporal variability. Mar Ecol Prog Ser 242:237-252

* Dempster T, Uglem I, Sánchez-Jerez P, Fernandez-Jover D, Bayle-Sempere J, Nilsen R (2009) Coastal salmon farms attract large and persistent aggregations of wild fish: an ecosystem effect. Mar Ecol Prog Ser 385:1-14

Wempster T, Sánchez-Jerez P, Uglem I, Bjørn PA (2010) Species-specific patterns of aggregation of wild fish around fish farms. Estuar Coast Shelf Sci 86:271-275

* Dempster T, Sánchez-Jerez P, Fernandez-Jover D, BayleSempere JT, Nilsen R, Bjørn PA, Uglem I (2011) Proxy measures of fitness suggest coastal fish farms can act as population sources and not ecological traps for wild gadoid fish. PLOS ONE 6:e15646

Fernández-Chacón A, Moland E, Espeland SH, Olsen EM (2015) Demographic effects of full vs. partial protection from harvesting: inference from an empirical beforeafter control-impact study on Atlantic cod. J Appl Ecol 52:1206-1215

Fernandez-Jover D, Jimenez JAL, Sánchez-Jerez P, BayleSempere JT, Giménez-Casalduero F, López FJM, Dempster $\mathrm{T}$ (2007) Changes in body condition and fatty acid composition of wild Mediterranean horse mackerel (Trachurus mediterraneus, Steindachner, 1868) associated to sea cage fish farms. Mar Environ Res 63:1-18

Fernandez-Jover D, Sánchez-Jerez P, Bayle-Sempere JT, Valle C, Dempster T (2008) Seasonal patterns and diets of wild fish assemblages associated with Mediterranean coastal fish farms. ICES J Mar Sci 65:1153-1160

Fernandez-Jover D, Arechavala-López P, Martinez-Rubio L, Tocher D and others (2011a) Monitoring the influence of marine aquaculture on wild fish communities: benefits and limitations of fatty acid profiles. Aquacult Environ
Interact 2:39-47

*Fernandez-Jover D, Martinez-Rubio L, Sánchez-Jerez P, Bayle-Sempere JT and others (2011b) Waste feed from coastal fish farms: a trophic subsidy with compositional side-effects for wild gadoids. Estuar Coast Shelf Sci 91: 559-568

*Forsgren E, Dupont S, Jutfelt F, Amundsen T (2013) Elevated $\mathrm{CO}_{2}$ affects embryonic development and larval phototaxis in a temperate marine fish. Ecol Evol 3: 3637-3646

Glover KA, Sørvik AGE, Karlsbakk E, Zhang Z, Skaala Ø (2013) Molecular genetic analysis of stomach contents reveals wild Atlantic cod feeding on piscine reovirus (PRV) infected Atlantic salmon originating from a commercial fish farm. PLOS ONE 8:e60924

Hale R, Swearer SE (2016) Ecological traps: current evidence and future directions. Proc R Soc B 283:20152647

Hale R, Treml EA, Swearer SE (2015) Evaluating the metapopulation consequences of ecological traps. Proc R Soc B 282:20142930

*Hallier JP, Gaertner D (2008) Drifting fish aggregation devices could act as an ecological trap for tropical tuna species. Mar Ecol Prog Ser 353:255-264

*Hansen T, Karlsen Ø, Taranger GL, Hemre GI, Holm JC, Kjesbu OS (2001) Growth, gonadal development and spawning time of Atlantic cod (Gadus morhua) reared under different photoperiods. Aquaculture 203:51-67

*Harboe T, Huse I, Øie G (1994) Effects of egg disinfection on yolk sac and first feeding stages of halibut (Hippoglossus hippoglossus L.) larvae. Aquaculture 119:157-165

Johansen LH, Jensen I, Mikkelsen H, Bjørn PA, Jansen PA, Bergh $\varnothing$ (2011) Disease interaction and pathogens exchange between wild and farmed fish populations with special reference to Norway. Aquaculture 315: $167-186$

KKarlsen Ø, Mangor-Jensen A (2001) A correlation between phototactic response and first-feeding of Atlantic halibut (Hippoglossus hippoglossus L.) larvae. Aquacult Res 32: 907-912

Karlsen $\varnothing$, van der Meeren T, Rønnestad I, Mangor-Jensen A, Galloway TF, Kjørsvik E, Hamre K (2015) Copepods enhance nutritional status, growth and development in Atlantic cod (Gadus morhua L.) larvae - can we identify the underlying factors? PeerJ 3:e902

* Kilambi RV, Adams JC, Wickizer WA (1978) Effects of cage culture on growth, abundance, and survival of resident largemouth bass (Micropterus salmoides). J Fish Res Board Can 35:157-160

Kirsch PE, Iverson SJ, Bowen WD, Kerr SR, Ackman RG (1998) Dietary effects on the fatty acid signature of whole Atlantic cod (Gadus morhua). Can J Fish Aquat Sci 55: 1378-1386

Kjesbu OS (1989) The spawning activity of cod, Gadus morhua L. J Fish Biol 34:195-206

*KKjesbu OS (1994) Time of start of spawning in Atlantic cod (Gadus morhua) females in relation to vitellogenic oocyte diameter, temperature, fish length and condition. J Fish Biol 45:719-735

Kjesbu OS, Witthames PR, Solemdal P, Walker MG (1990) Ovulatory rhythm and a method to determine the stage of spawning in Atlantic cod (Gadus morhua). Can J Fish Aquat Sci 47:1185-1193

Kjesbu OS, Klungsøyr J, Kryvi H, Witthames PR, Walker MG (1991) Fecundity, atresia, and egg size of captive Atlantic cod (Gadus morhua) in relation to proximate body com- 
position. Can J Fish Aquat Sci 48:2333-2343

Kjesbu OS, Solemdal P, Bratland P, Fonn M (1996) Variation in annual egg production in individual captive Atlantic cod (Gadus morhua). Can J Fish Aquat Sci 53:610-620

Kloskowski J (2012) Fish stocking creates an ecological trap for an avian predator via effects on prey availability. Oikos 121:1567-1576

Knutsen GM, Tilseth S (1985) Growth, development, and feeding success of Atlantic cod larvae Gadus morhua related to egg size. Trans Am Fish Soc 114:507-511

Knutsen H, Olsen EM, Espeland SH (2016) Norwegian coastal cod south of $62^{\circ} \mathrm{N}$ (in Norwegian). In: Institute for Marine Research Report (Havforskningsrapporten). Norwegian Institute for Marine Research (Havforskningsinstituttet), Bergen

Kutti T, Ervik A, Hansen PK (2007) Effects of organic effluents from a salmon farm on a fjord system. I. Vertical export and dispersal processes. Aquaculture 262: 367-381

Lambert Y, Dutil JD (1997) Can simple condition indices be used to monitor and quantify seasonal changes in the energy reserves of cod (Gadus morhua)? Can J Fish Aquat Sci 54:104-112

KLambert Y, Dutil JD (2000) Energetic consequences of reproduction in Atlantic cod (Gadus morhua) in relation to spawning level of somatic energy reserves. Can J Fish Aquat Sci 57:815-825

Lavens P, Lebegue E, Jaunet H, Brunel A, Dhert P, Sorgeloos $P$ (1999) Effect of dietary essential fatty acids and vitamins on egg quality in turbot broodstocks. Aquacult Int $7: 225-240$

* Le Cren ED (1951) The length-weight relationship and seasonal cycle in gonad weight and condition in the perch (Perca fluviatilis). J Anim Ecol 20:201-219

Marteinsdottir G, Steinarsson A (1998) Maternal influence on the size and viability of Iceland cod Gadus morhua eggs and larvae. J Fish Biol 52:1241-1258

Mazorra C, Bruce M, Bell JG, Davie A and others (2003) Dietary lipid enhancement of broodstock reproductive performance and egg and larval quality in Atlantic halibut (Hippoglossus hippoglossus). Aquaculture 227: 21-33

McConnell A, Routledge R, Connors B (2010) Effect of artificial light on marine invertebrate and fish abundance in an area of salmon farming. Mar Ecol Prog Ser 419: $147-156$

Meier S, Mjøs SA, Joensen H, Grahl-Nielsen O (2006) Validation of a one-step extraction/methylation method for determination of fatty acids and cholesterol in marine tissues. J Chromatogr A 1104:291-298

Morgan MJ, Wilson CE, Crim LW (1999) The effect of stress on reproduction in Atlantic cod. J Fish Biol 54:477-488

Naas KE, Næss T, Harboe T (1992) Enhanced first feeding of halibut larvae (Hippoglossus hippoglossus L.) in green water. Aquaculture 105:143-156

Neat FC, Wright PJ, Zuur AF, Gibb IM and others (2006) Residency and depth movements of a coastal group of Atlantic cod (Gadus morhua L.). Mar Biol 148:643-654

Olsen EM, Moland E (2011) Fitness landscape of Atlantic cod shaped by harvest selection and natural selection. Evol Ecol 25:695-710

Olsen EM, Heupel MR, Simpfendorfer CA, Moland E (2012) Harvest selection on Atlantic cod behavioral traits: implications for spatial management. Ecol Evol 2:1549-1562

Olsen SA, Hansen PK, Givskud H, Ervik A, Samuelsen OB
(2015) Changes in fatty acid composition and stable isotope signature of Atlantic cod (Gadus morhua) in response to laboratory dietary shifts. Aquaculture 435: $277-285$

Otterå H, Skilbrei OT (2014) Possible influence of salmon farming on long-term resident behaviour of wild saithe (Pollachius virens L.). ICES J Mar Sci 71:2484-2493

* Otterå H, Agnalt A, Jorstad K (2006) Differences in spawning time of captive Atlantic cod from four regions of Norway, kept under identical conditions. ICES J Mar Sci 63: 216-223

* Patten MA, Kelly JF (2010) Habitat selection and the perceptual trap. Ecol Appl 20:2148-2156

*Porter MJ, Duncan N, Mitchell D, Bromagea N (1999) The use of cage lighting to reduce plasma melatonin in Atlantic salmon (Salmo salar) and its effects on the inhibition of grilsing. Aquaculture 176:237-244

R Core Team (2016) R: a language and environment for statistical computing. R Foundation for Statistical Computing, Vienna

Rahman MM, Gasparini C, Turchini GM, Evans JP (2014) Experimental reduction in dietary omega-3 polyunsaturated fatty acids depresses sperm competitiveness. Biol Lett 10:20140623

Rainuzzo JR, Reitan KI, Olsen Y (1997) The significance of lipids at early stages of marine fish: a review. Aquaculture 155:103-115

Reitan KI, Rainuzzo JR, Olsen Y (1994) Influence of lipid composition of live feed on growth, survival and pigmentation of turbot larvae. Aquacult Int 2:33-48

Remeš V (2003) Effects of exotic habitat on nesting success, territory density, and settlement patterns in the blackcap (Sylvia atricapilla). Conserv Biol 17:1127-1133

* Robertson BA, Hutto RL (2006) A framework for understanding ecological traps and an evaluation of existing evidence. Ecology 87:1075-1085

Robichaud D, Rose GA (2004) Migratory behaviour and range in Atlantic cod: inference from a century of tagging. Fish Fish 5:185-214

Salze G, Tocher DR, Roy WJ, Robertson DA (2005) Egg quality determinants in cod (Gadus morhua L.): egg performance and lipids in eggs from farmed and wild broodstock. Aquacult Res 36:1488-1499

Sargent J, Bell G, McEvoy L, Tocher D, Estevez A (1999a) Recent developments in the essential fatty acid nutrition of fish. Aquaculture 177:191-199

Sargent J, McEvoy L, Estevez A, Bell G, Bell M, Henderson J, Tocher D (1999b) Lipid nutrition of marine fish during early development: current status and future directions. Aquaculture 179:217-229

Schneider CA, Rasband WS, Eliceiri KW (2012) NIH Image to ImageJ: 25 years of image analysis. Nat Methods 9: 671-675

Sclafani M, Taggart CT, Thompson KR (1993) Condition, buoyancy and the distribution of larval fish: implications for vertical migration and retention. J Plankton Res 15: 413-435

Sherley RB, Ludynia K, Dyer BM, Lamont T and others (2017) Metapopulation tracking juvenile penguins reveals an ecosystem-wide ecological trap. Curr Biol 27: 563-568

Shima JS, Swearer SE (2010) The legacy of dispersal: larval experience shapes persistence later in the life of a reef fish. J Anim Ecol 79:1308-1314

Skilbrei OT, Otterå H (2016) Vertical distribution of saithe 
(Pollachius virens) aggregating around fish farms. ICES J Mar Sci 73:1186-1195

Skjæraasen JE, Nilsen T, Kjesbu OS (2006) Timing and determination of potential fecundity in Atlantic cod (Gadus morhua). Can J Fish Aquat Sci 63:310-320

Svåsand T (1990) Comparisons of migration patterns of wild and recaptured reared coastal cod, Gadus morhua L., released in a small fjord in western Norway. Aquacult Res 21:491-495

Trippel EA (2010) Pathway of effects of artificial light on non-target organisms at aquaculture sites in Canada. DFO Can Sci Advis Sec Res Doc 2010/023. www.dfompo.gc.ca/csas-sccs/publications/resdocs-docrech/2010/ 2010_023-eng.htm

Uglem I, Bjørn PA, Dale T, Kerwath S and others (2008) Movements and spatiotemporal distribution of escaped farmed and local wild Atlantic cod (Gadus morhua L.). Aquacult Res 39:158-170

Uglem I, Dempster T, Bjørn PA, Sánchez-Jerez P, Økland F (2009) High connectivity of salmon farms revealed by aggregation, residence and repeated movements of wild fish among farms. Mar Ecol Prog Ser 384:251-260

Vallin L, Nissling A (2000) Maternal effects on egg size and egg buoyancy of Baltic cod, Gadus morhua: implications for stock structure effects on recruitment. Fish Res 49: 21-37

van der Meeren T, Ivannikov VP (2006) Seasonal shift in spawning of Atlantic cod (Gadus morhua L.) by photope-

Editorial responsibility: Ian Fleming, St. John's, Newfoundland and Labrador, Canada riod manipulation: egg quality in relation to temperature and intensive larval rearing. Aquacult Res 37:898-913

* van der Meeren T, Karlsen Ø, Liebig PL, Mangor-Jensen A (2014) Copepod production in a saltwater pond system: a reliable method for achievement of natural prey in startfeeding of marine fish larvae. Aquacult Eng 62:17-27

*Wasta Z, Mjøs SA (2013) A database of chromatographic properties and mass spectra of fatty acid methyl esters from omega-3 products. J Chromatogr A 1299:94-102

*Weldon AJ, Haddad NM (2005) The effects of patch shape on indigo buntings: evidence for an ecological trap. Ecology 86:1422-1431

White CA, Dworjanyn SA, Nichols PD, Mos B, Dempster T (2016) Future aquafeeds may compromise reproductive fitness in a marine invertebrate. Mar Environ Res 122: $67-75$

* White CA, Bannister RJ, Dworjanyn SA, Husa V, Nichols PD, Kutti T, Dempster T (2017a) Consumption of aquaculture waste affects the fatty acid metabolism of a benthic invertebrate. Sci Total Environ 586:1170-1181

WWite CA, Nichols PD, Ross DJ, Dempster T (2017b) Dispersal and assimilation of an aquaculture waste subsidy in a low productivity coastal environment. Mar Pollut Bull 120:309-321

* White CA, Woodcock SH, Bannister RJ, Nichols PD (2017c) Terrestrial fatty acids as tracers of finfish aquaculture waste in the marine environment. Rev Aquacult, doi: 10.1111/raq. 12230

Submitted: July 19, 2017 ; Accepted: June 4, 2018

Proofs received from author(s): August 8, 2018 